\title{
Evaluating the environmental benefits of industrial symbiosis: discussion and demonstration of a new approach
}

Anna Wolf and Magnus Karlsson

The self-archived postprint version of this journal article is available at Linköping University Institutional Repository (DiVA):

http:/ / urn.kb.se/ resolve?urn=urn:nbn:se:liu:diva-12645

N.B.: When citing this work, cite the original publication.

Wolf, A., Karlsson, M., (2008), Evaluating the environmental benefits of industrial symbiosis: discussion and demonstration of a new approach, Progress in Industrial Ecology, An International J ournal, 5(5-6), 502-517. https:// doi.org/ 10.1504/ PIE.2008.023413

Original publication available at:

https:/ / doi.org/ 10.1504/ PIE.2008.023413

Copyright: Inderscience

http:// www.inderscience.com/ 


\title{
Evaluating the environmental benefits of industrial symbiosis: discussion and demonstration of a new approach
}

\author{
Anna Wolf and Magnus Karlsson \\ Department of Management and Engineering \\ Division of Environmental Technology and Management \\ Linköping Institute of Technology \\ SE 58183 Linköping, Sweden
}

\begin{abstract}
In this study, a computer model that includes a pulp mill, a paper mill, a sawmill and a biofuel upgrading plant, together with the possible energy and material exchanges between them, is used to evaluate the environmental impact of a possible Industrial Symbiosis (IS) arrangement in the forest industry. The method used is called the Method for analysis of INDustrial energy systems (MIND), which is an optimisation method based on mixed integer linear programming. In this study, the emission of the greenhouse gas carbon dioxide $\left(\mathrm{CO}_{2}\right)$ from the symbiosis system is compared to that from a system of stand-alone plants. We also discuss some of the reasons why measurement of environmental benefits is problematic, as well as the applicability of the method compared to some other frequently used methods for accounting for $\mathrm{CO}_{2}$ emissions and other environmental issues.
\end{abstract}

Keywords: industrial symbiosis; environmental assessment; MIND method; optimisation; $\mathrm{CO}_{2}$ emissions.

\section{Introduction}

Industrial Ecology (IE) is an interdisciplinary field of research engaging environmental scientists, engineers, natural scientists, social scientists, and business and organisational researchers. The IE tool box borrows from all the contributing disciplines and includes many different approaches such as case studies, material and energy flow analyses, Life Cycle Assessment (LCA) and design for environment (van Berkel et al., 1997; Graedel and Allenby, 2003), all of which have many applications as well as many shortcomings. The tools used for environmental systems analysis and energy systems analysis, however, are seldom applied to the subfield of Industrial Symbiosis (IS). The by-product synergies linked to industrial ecosystems and IS are often assumed to provide environmental benefits, contributing to the overall goal of sustainability that IE endeavours to achieve. However, the lack of studies in the field confirming this assumption is obvious. Very few attempts have been made to quantify these benefits, either theoretically or through case studies.

A quantitative assessment of the IS complex in Kalundborg was made by Brings Jacobsen (2006), who found both substantial and minor environmental benefits connected to the IS project. The study includes water and steam exchanges. For the heat-related exchanges, the estimations are based on data from the companies compared to hypothetical stand-alone plants. However, it lacks a detailed engineering calculation of the fullscale cogeneration effect of the IS relationships (Brings Jacobsen, 2006). Some estimations of savings in water, oil equivalents and natural gypsum have also been made for the Kalundborg IS network (Symbiosis Institute, 2007; Christensen, 2007), but these are typically presented without accounting for assumptions or the method of calculations. Singh et al. (2006) performed an LCA-type environmental impact assessment for the different design schemes of an industrial ecosystem using a software tool. However, the different design schemes used included different plants and processes as well as new products, which makes it difficult to see to what extent the environmental benefits can be attributed to IS in particular. Chertow and Lombardi (2005) quantified the economic and environmental benefits of a proposed IS network in Puerto Rico, similar to the Kalundborg complex, and concluded that IS has less environmental pressure. The study, however, shows some results that conflict with this conclusion. For example, the steam exchanges lead to lower emissions of $\mathrm{SO}_{2}, \mathrm{NO}_{x}$ and particulates, but higher emissions of carbon dioxide $\left(\mathrm{CO}_{2}\right)$.

\section{Objective}

One of the reasons for the lack of studies quantifying IS is the difficulty of performing such studies while taking all the necessary parameters into account. The objective of this paper is to illustrate the complexity of environmental evaluation, using a computer model of an IS arrangement in the forest industry that focuses on $\mathrm{CO}_{2}$ emissions. An attempt is also made to draw conclusions as to the advantages of an IS-configured system compared to the same system operated in stand-alone mode. The parameters that are similar in both systems, such as raw material and the production of main products, are excluded, but indirect emissions from external processes that are influenced when changes are made to the system are taken into account.

\section{Environmental assessment}


One of the most commonly used tools for environmental assessment is LCA, which also has a central role in IE (for an overview of the applications of LCA in IE, see, e.g., Graedel and Allenby, 2003). This method is widely used and has many applications, but has also been criticised (e.g., Finnveden, 2000; Ayres, 1995; Ehrenfeld, 1998). Some difficulties concerning LCA and other environmental assessment tools that have been discussed in the literature are issues of boundaries and time perspectives, allocation problems, lack of knowledge regarding how certain emissions affect the environment, data gaps, and the valuation and weighting of different environmental problems (e.g., Ammenberg, 2003; Finnveden, 2000; Russel et al., 2005).

One uncertainty in environmental assessment is that the results often depend on the properties of the surroundings. Finnveden and Ekvall (1998), for example, found that when comparing the recycling of paper to incineration, it is important to consider, for example, what fuel is used for heat production and what happens to the wood that is saved if paper is recycled. Finnveden (2000) suggests that such aspects can be determined (at least in theory) in descriptive studies, but are very uncertain in change-oriented studies, since the future is always uncertain. Scenario analysis can be used to describe the future (e.g., Börjesson et al., 2006), but is always uncertain and will furthermore never produce simple results such as 'product a is better than product b' or 'industry $\mathrm{x}$ will have impact $\mathrm{y}$ on the environment'.

To overcome the complexity of environmental assessment, indicators can be used to describe the environmental pressure from companies (e.g., Tyteca et al., 2002; Svensson et al., 2006). There are physical indicators - energy and water inputs, waste generation, emissions into air, emissions into water; business indicators, such as ISO 14001/EMAS certification; and impact indicators, for example, emissions of ozone-depleting substances into air (Tyteca et al., 2002). The use of indicators enables some of the problems in environmental assessment to be avoided, such as evaluating, weighing and deciding how emissions affect the environment. However, concerns such as system boundaries, emissions accounting and allocation may remain, depending on the type of indicator. It is also important to realise that indicators often reflect the environmental issues in focus at the time, and that their usefulness might depend on the type of process or product studied and on the system they operate in (Svensson et al., 2006).

One of the grand objectives for IE and sustainability today is addressing the growing concern about climate change (e.g., Graedel and Allenby, 2003). The energy sector accounts for a large part of the contribution to $\mathrm{CO}_{2}$ emissions, and energy indicators are often used to measure companies' environmental performance (Svensson et al., 2006). In energy systems research, $\mathrm{CO}_{2}$ emissions are often used as the only indicator (although not using that specific terminology). Although this simplification might seem an easy way of assessing environmental performance, some difficulties remain in accounting for $\mathrm{CO}_{2}$ from energy use. Accounting for emissions from energy use and the production of energy carriers is also an important parameter in LCA and other environmental assessment tools. Grönkvist et al. (2003) showed that this is a problematic step leading to very different results depending on the assumptions made. Depending on how the electricity or heat used is assumed to be produced (average annual production, different types of marginal production, labelled electricity, etc.), the emissions vary considerably. In LCA, the average grid electricity production is mostly used, at least in practice ${ }^{1}$, although the usefulness of the marginal electricity approach is also being discussed (Finnveden and Moberg, 2005; Ekvall et al., 2005). One common view is that marginal data should be used for change-oriented studies, whereas average data is more appropriate for accounting studies (Ekvall, 2002; Finnveden and Moberg, 2005; Ekvall et al., 2005). Some authors also suggest that labelled electricity might be appropriate (Kåberger and Karlsson, 1998). In the field of energy systems analysis, opinions differ, but many authors suggest, or use, some type of present or future marginal approach (e.g., Sjödin and Grönkvist, 2004; Werner, 2001; Trygg, 2006; Knutsson et al., 2006; Carlson, 2003). Grönkvist (2005) suggests a more pragmatic view, where the analysis should be focused on the specific situation and openness to change is essential. This is contradictory to the discussion, for example in LCA, that it is important to endeavour to achieve greater harmonisation of the methodology (Finnveden, 2000), which is also reflected in the existing ISO standards.

\section{...and industrial symbiosis in particular}

Having crossed through the minefield of environmental assessment in general, some additional questions arise regarding the environmental assessment of IS systems. In order to understand these, it is important to consider what is meant by the environmental assessment of IS. Chertow and Lombardi (2005) suggest, "The

\footnotetext{
${ }^{1}$ For example, the Swedish Forest Industry Federation state, in their code of conduct for LCA, "When evaluating electrical energy consumption the national grid production mix shall be used" without references to the nature of the study (descriptive/attributional, etc.) (Swedish Forest Industry Federation, 2007).
} 
environmental benefits of industrial symbiosis are quantified by measuring the changes in consumption of natural resources, and in emissions to air and water, through increased recycling of materials and energy.” Although this way of accounting for the benefits may exclude secondary effects, such as efficient use of buildings, personnel, the possibility for common deliveries and use of services which might reduce transportation, it is still a reasonable way of simplifying the system and focusing on the effects of IS. There are, however, some difficulties in performing such a quantification.

The first problem that arises is how the benefits from IS can be separated from other factors that might influence the environmental impact of the participating entities. Using a model, it is possible to compare the performance of the integrated IS system to the performance of the system directly if all entities are operated stand-alone. However, this may not be entirely fair since different technologies might be advantageous, depending on the degree of integration of the system. On the other hand, if the environmental impact of an IS system is evaluated using some kind of measurement on a real-life system, it is difficult to see if the environmental benefits are due to the IS or to other factors influencing the companies (cf. Ammenberg (2003) for a similar discussion on standardised environmental management systems). For example, if the emissions of $\mathrm{CO}_{2}$ from the industries are lower than from traditional industry, the question may be asked if that is due to the IS connections, to a specific choice of technology or to other cleaner production measures. If the environmental benefits are due to the use of residuals and by-products as raw material, issues regarding the alternative use of these by-products have to be considered. For an IS network such as Kalundborg, which has developed spontaneously over several decades, it is difficult to decide which system configuration should be used as reference when calculating savings and other environmental benefits (Christensen, 2007). For example, should the system be compared to the original system, which may be completely different, or to the most likely alternative development? Brings Jacobsen (2006) states that it is difficult to perform a detailed engineering calculation of the effects of the Kalundborg IS since conditions have changed over the years and because access to relevant technical data and decision scenarios is difficult in the historical perspective.

There is also an allocation problem when considering industrial ecosystems and IS, i.e., how the environmental pressure, or the environmental benefits from IS, should be allocated between the participating entities. Although this may be of no importance to the 'environment' as such (the atmosphere does not really care about where the $\mathrm{CO}_{2}$ molecules came from, the greenhouse effect will still be the same), it is of utmost importance to the participating entities since the environmental performance of specific entities influences taxes, subsidies, environmental consent, etc. It is also important in LCA studies of products that are produced in IS systems, where allocation is a classic problem. Ekvall and Weidema (2004) suggest some approaches for the allocation problem in multifunctional approaches. They suggest different approaches, or a combination thereof, for different kinds of multifunctional processes, and for recycling. If the IS system is seen as a multifunctional process with many different products and dependencies, the allocation problem becomes very complex since the relationships between different production units may be complex, including raw material, by-products, recycling of waste material, common systems for heat delivery, water use, etc., all at once.

When assessing the environmental benefits of IS, it is also important to consider the system boundaries to ensure that the systems compared really are comparable. Otherwise, there is a risk of inconsistency in the comparison, where the two systems have different boundary conditions or include completely different processes. If processes are added to or removed from the system, alternative uses and production have to be considered. Also, to assure the relevance of the results, it is important to clearly show which system boundaries have been used. Wolf et al. (2007) concluded that it is important to have a flexible system boundary, looking at the system from different perspectives and at different levels to find the best uses for existing energy and material streams.

\section{The MIND method}

In this study, we use a model of a simple IS system to illustrate the complexity of environmental evaluation. The system of stand-alone production is compared to that of integrated production using a Method for analysis of INDustrial energy systems (MIND) model, which is a mixed-integer linear programming tool (Karlsson and Sandberg, 2007). This way, the effects of the integration can be evaluated and decoupled from other effects. It is also possible to use the MIND method to compare different design schemes and processes, as well as to find potential improvements in the structure. In this study, $\mathrm{CO}_{2}$ emissions are optimised, but the most common objective is system costs, and it is also possible to use a multi-objective approach (Sandberg and Larsson, 2006). The model used in this study (Figure 1) is adapted from Karlsson and Wolf (2008), where the economic evaluation of the system has been carried out. In this study, the same model is used to evaluate $\mathrm{CO}_{2}$ emissions instead of the system costs. 


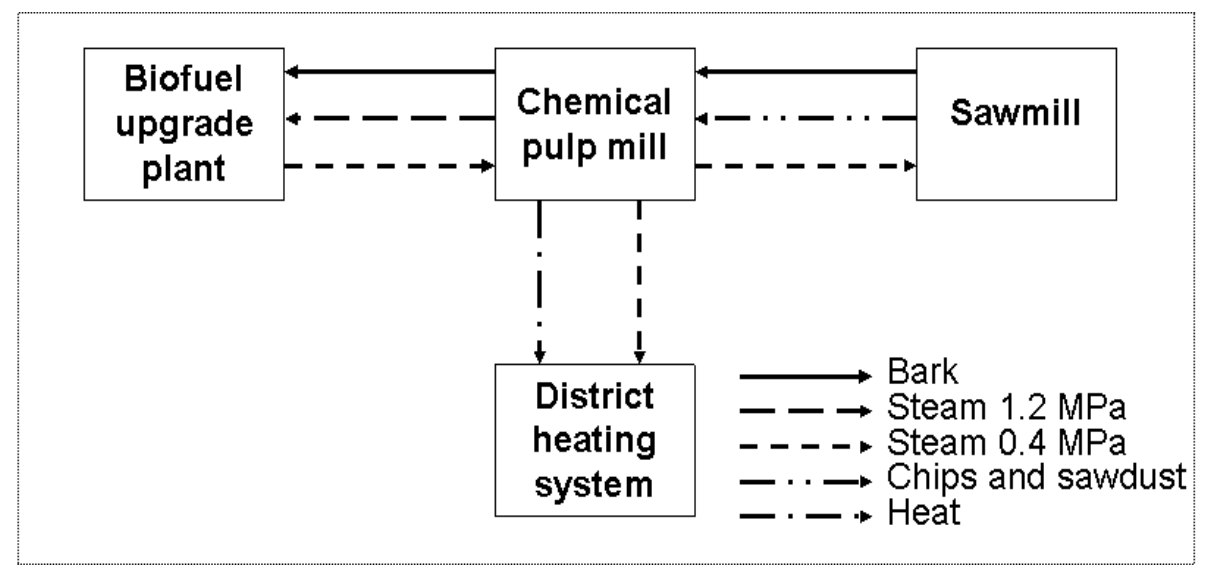

Figure 1 A schematic picture of the system including possible material and fuel exchanges Note: The system boundary used in the study is drawn around all subsystems.

Using the MIND method, a model of the plants is constructed, made up of nodes and branches. A branch represents a flow of any kind while a node may represent a component, a process unit, or a complete process line. Figure 2 is a screen dump of the graphical interface, reMIND, and shows one of the models used in this study. The objective chosen (in this case the $\mathrm{CO}_{2}$ emissions) is then minimised using a commercial optimisation solver (CPLEX).

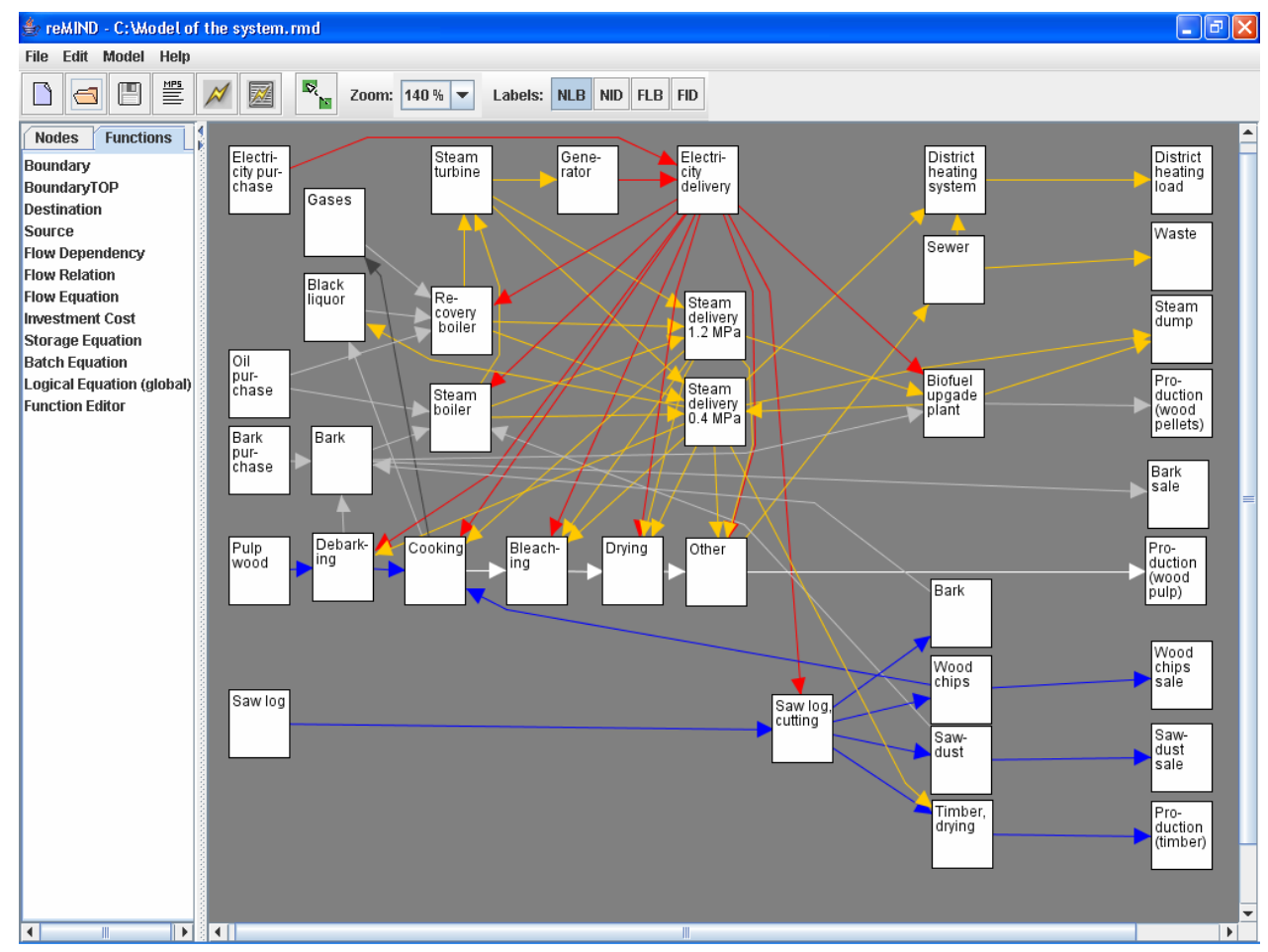

Figure 2 A screen dump of the system as shown in the reMIND interface

The system boundary is drawn to include the same units in all cases, operated either in stand-alone mode or integrated in an IS network as suggested in Figure 1. Parameters that are similar in both systems, such as raw material and production of main products, are excluded since the objective is to compare the integrated system to the stand-alone system in order to evaluate the benefits of IS decoupled from other effects. Indirect emissions from electricity produced outside of the system are accounted for using different sets of boundary conditions and assumptions, as explained below. For the stand-alone district heating system, the possible fuels for base load and 
peak load are biofuel or oil ${ }^{2}$. The sawmill and the biofuel upgrading plant have biofuel boilers that cover the heat demand in stand-alone operation.

\section{Input data and assumptions}

The pulp mill in the model is based on an existing mill with an annual production capacity of 550000 tonnes. The sawmill is also based on data from an existing sawmill with an annual production of $100000 \mathrm{~m} 3 \mathrm{sawn}$ wood. The modelled production of wood pellets at the biofuel upgrading plant is 40000 tonnes/year. As for the plants, the input data for the district heating system is taken from a real system. It is a small system, equivalent to 22 GWh per year. A thorough description of input data for the plants can be found in Karlsson and Wolf (2008). To illustrate the differences in results depending on the assumptions made, different emissions accounting models are used. The $\mathrm{CO}_{2}$ emissions from different fuels can be found in Table 1 (IPCC, 1997). Based on the $\mathrm{CO}_{2}$ emission factors and the efficiencies of different production units, the $\mathrm{CO}_{2}$ emissions from heat and power production can be calculated. Table 2 shows the $\mathrm{CO}_{2}$ emissions from electricity depending on the assumed model for alternative power production. As mentioned before, average data is often used in LCA and might also be appropriate for descriptive studies, although this is open to discussion. Some kind of marginal data is often more appropriate when change-oriented studies are made. For Sweden, coal condensing power has been assumed to be the short-term marginal power production method, and for longer time perspectives, taking new technologies into account, the Natural Gas Combined Cycle (NGCC) is the marginal power production method (SEA, 2002).

Table 1 CO2 emissions from different fuels (IPCC, 1997)

\begin{tabular}{ll}
\hline Fuel & $\mathrm{CO}_{2}$ emission factor $\left(\mathrm{kg} \mathrm{CO}_{2} \mathrm{MWh}^{-1}\right.$ fuel $)$ \\
\hline Bituminous coal & 341 \\
Residual fuel oil & 279 \\
Dry natural gas & 202 \\
Biofuel & 0 \\
\hline
\end{tabular}

Table $2 \mathrm{CO}_{2}$ emissions from electricity for different accounting models

\begin{tabular}{ll}
\hline Model & $\mathrm{CO}_{2}$ emissions $\left(\mathrm{kg} \mathrm{CO}_{2} \mathrm{MWh}^{-1}\right.$ electricity) \\
\hline Marginal Coal & $974^{*}$ \\
Marginal New Technology (NGCC) & $337^{*}$ \\
Average Swedish Production & $11^{* *}$ \\
\hline
\end{tabular}

* Calculated from Grönkvist et al. (2003).

** SEA (2000).

It is usually assumed that the net $\mathrm{CO}_{2}$ emissions from biofuel are zero, although this has been debated in e.g., Grönkvist et al. (2003). This assumption is only true if the biofuel used is regrown at the same pace as it is being used, and as long as biofuel is an unlimited resource. This assumption could also lead to the misinterpretation that there is no reason, from a $\mathrm{CO}_{2}$ and a resource perspective at least, to use biofuel as efficiently as possible. However, if biofuel is a limited resource, it would mean that biofuel saved could replace some other type of fuel in the system, and the other way around - if additional biofuel is needed, it has to be taken from some other unit, leading to that unit having to use other fuels instead. Grönkvist et al. (2003) argue that a comparison with coal would be natural since biofuel may replace coal in many applications without any extensive technical modifications. Therefore, in the limited biofuel model, $\mathrm{CO}_{2}$ emissions from biofuel have been assigned the same values as for coal. To illustrate the influence of different assumptions on the results when analysing the environmental effects of a specific system, the $\mathrm{CO}_{2}$ emissions were calculated using different assumptions regarding the origin of electricity and the emissions from biofuel. For each of the electricity accounting models, one case where biofuel is regarded as unlimited and one case where it is assumed to be limited were used, adding up to six cases (Table 3).

\footnotetext{
2 The demand in the peak hours is $8.9 \mathrm{MW}$. The maximum heat delivery from the biofuel boiler is $4.44 \mathrm{MW}$ and the maximum heat delivery from the oil boiler $4.98 \mathrm{MW}$. Annually, $98.6 \%$ of the energy deliveries are covered by the base load. Depending on the assumptions, the choice of fuel between base load and peak load varies.
} 
Table 3 Assumption models

\begin{tabular}{lll}
\hline Model & $\begin{array}{l}\text { Emissions from biofuel } \\
\left(\mathrm{kg} \mathrm{CO}_{2} \mathrm{MWh}^{-1}\right)\end{array}$ & $\begin{array}{l}\text { Emissions from electricity }(\mathrm{kg} \\
\left.\mathrm{CO}_{2} \mathrm{MWh}^{-1}\right)\end{array}$ \\
\hline $\begin{array}{l}\text { Marginal Coal, Biofuel } \\
\begin{array}{l}\text { Unlimited } \\
\text { Marginal NGCC, Biofuel }\end{array}\end{array}$ & 0 & 974 \\
$\begin{array}{l}\text { Unlimited } \\
\begin{array}{l}\text { Average Grid, Biofuel } \\
\text { Unlimited }\end{array}\end{array}$ & 0 & 337 \\
$\begin{array}{l}\text { Marginal Coal, Biofuel Limited } \\
\text { Marginal NGCC, Biofuel }\end{array}$ & 341 & 11 \\
$\begin{array}{l}\text { Limited } \\
\text { Average Grid, Biofuel Limited }\end{array}$ & 341 & 974 \\
\hline
\end{tabular}

\section{Results and analysis}

\section{Results from $\mathrm{CO}_{2}$ optimisation}

The results of the optimisation are shown in Table 4. In all cases, the results show that less $\mathrm{CO}_{2}$ is released from the integrated system compared to the stand-alone system. In all the cases also, the steam dumping from the pulp mill decreases for the IS system compared to the stand-alone system, since the excess steam can be used in the district heating system and for drying of wood and biomass at the sawmill and at the biofuel upgrading plant.

Table 4 Decrease in $\mathrm{CO}_{2}$ emissions from the integrated system compared to the stand-alone system

\begin{tabular}{lll}
\hline Model & $\begin{array}{l}\text { Biofuel Unlimited, } \\
\text { tons } \mathrm{CO}_{2} / \text { year }\end{array}$ & $\begin{array}{l}\text { Biofuel Limited, } \\
\text { tons } \mathrm{CO}_{2} / \text { year }\end{array}$ \\
\hline Marginal Coal & 4600 & 26000 \\
Marginal NGCC & 1700 & 25000 \\
Average Grid & 160 & 37000 \\
\hline
\end{tabular}

In the Biofuel Unlimited cases, the savings in $\mathrm{CO}_{2}$ for IS are largest when marginal coal is assumed to be the alternative electricity production, and lowest if data for average Swedish electricity production is assumed. The reason for this is that the pulp mill produces electricity, which in the Biofuel Unlimited cases is assumed to have net zero emissions of $\mathrm{CO}_{2}$ since the steam delivered to the turbine is produced by biofuel. Thus, as the steam delivered to the turbine has zero emissions of $\mathrm{CO}_{2}$, as much electricity as possible is produced in the turbine. The relationship between admission steam, 4-bar steam and 12-bar steam, set by the turbine curve, is the limiting factor as regards the amount of electricity produced. In the integrated cases more electricity is produced compared to the stand-alone cases, since the excess steam can be used in the District Heating Network (DHN) and for drying wood and biomass at the sawmill and the biofuel upgrading plant. Consequently, the amount of electricity that has to be purchased from the grid is lower. This influences the results more in the Marginal Coal case and in the Marginal NGCC case than in the Average Grid case because the electricity that is purchased from the grid has lower $\mathrm{CO}_{2}$ emissions in the Average Grid case compared to the others.

In the Biofuel Limited cases, the savings in $\mathrm{CO}_{2}$ are larger in the Average Grid case than in the Marginal NGCC case and the Marginal Coal case. In these cases the only boiler that produces steam is the recovery boiler, and when using black liquor in the recovery boiler the net influence on the $\mathrm{CO}_{2}$ emissions is zero, as the amount of black liquor produced is the same in both the integrated cases and the stand-alone cases. The biofuel used, on the other hand, is assigned the same value for $\mathrm{CO}_{2}$ emissions as coal, and if more electricity is produced using biofuel, the net $\mathrm{CO}_{2}$ emissions would be larger than for electricity bought from the grid. The result is that no biofuel at all is combusted in these cases. In the integrated Average Grid case and the Marginal NGCC case, 
there is no incentive to use the increased heat and steam demand as a basis to produce more electricity, as this would in fact result in a demand to combust biofuel. Instead, the increased heat and steam demand leads to less steam passing through the turbine. This is a consequence of it not being possible to pass all steam through the turbine, because the amount of steam from combusting black liquor is insufficient both to cover the steam demand in the processes and to produce electricity; some steam is therefore delivered directly to the processes from the recovery boiler. Thus, when the heat and steam demand is increased, less steam can pass the turbine. The result is that less electricity is produced on-site and more electricity is purchased in the integrated cases compared to the stand-alone cases. The integration also entails an increased potential for selling biofuel, compared to the stand-alone cases, as the biofuel is not combusted. The decrease in $\mathrm{CO}_{2}$ emissions is in fact a result of selling as much biofuel as possible. The difference in $\mathrm{CO}_{2}$ emissions between the Average Grid case and the Marginal NGCC case is the different amount of $\mathrm{CO}_{2}$ emissions from electricity purchases; otherwise the results are the same.

The reason for the decrease in $\mathrm{CO}_{2}$ emissions in the integrated Marginal Coal case when biofuel is limited, compared to stand-alone, is partly the same as for the Average Grid case and for the Marginal NGCC case. All biofuel is sold in this case and the only boiler in operation is the recovery boiler. However, as the $\mathrm{CO}_{2}$ emissions from electricity purchase are higher than if oil is used to produce steam, the recovery boiler is boosted with oil combustion. There is also an incentive to slightly increase electricity production when integrating, but only to the extent that no steam is dumped. The use of oil to produce electricity leads to an additional opportunity to decrease the $\mathrm{CO}_{2}$ emissions in the Marginal Coal case compared to the other cases. This extra opportunity results in a greater potential for decreasing $\mathrm{CO}_{2}$ emissions for the Marginal Coal case compared to the Marginal NGCC case (see Table 3), as the electricity purchase increase in the latter generates large $\mathrm{CO}_{2}$ emissions and the increased use of oil in the Marginal Coal case does not involve that amount of $\mathrm{CO}_{2}$ emissions. However, the lower $\mathrm{CO}_{2}$ emissions due to increased electricity production in the Marginal Coal case do not fully compensate for the higher $\mathrm{CO}_{2}$ emissions from using oil, compared to the Average Grid case (see Table 4).

The savings are generally much greater in the Biofuel Limited cases. The reason is, first and foremost, the fact that a change in the use of biofuel leads to large $\mathrm{CO}_{2}$ emission reductions in the Biofuel Limited cases. The reduced electricity purchase in the Biofuel Unlimited cases does not balance the situation, even though the Biofuel Limited cases increase electricity purchase. Also, the stand-alone DHN generates much higher emissions if biofuel is considered to be a limited resource (since the base load of the DHN is biofuel), and thus the incentives to use waste heat from the pulp mill in the DHN are higher than if biofuel is considered to be an unlimited resource.

\section{Comparison with economic optimisation}

It must be pointed out that the MIND method is an optimisation tool, which means that the computer program chooses the optimal solution for the system, minimising the objective chosen, such as cost and emissions. In this study, the optimisation was done with $\mathrm{CO}_{2}$ emissions as the objective. This might lead to solutions that are unrealistic in a real system due to high costs. In Table 5 the decrease in $\mathrm{CO}_{2}$ emissions in the integrated cases and the stand-alone cases, when using economic optimisation as the basis (Karlsson and Wolf, 2008), is shown for comparison.

Table 5 Decrease in $\mathrm{CO}_{2}$ emissions from the integrated system compared to the stand-alone system when using economical optimisation as the basis

\begin{tabular}{lll}
\hline Model & $\begin{array}{l}\text { Biofuel Unlimited, } \\
\text { tons } \mathrm{CO}_{2} / \text { year }\end{array}$ & $\begin{array}{l}\text { Biofuel Limited, } \\
\text { tons } \mathrm{CO}_{2} / \text { year }\end{array}$ \\
\hline Marginal Coal & 2500 & 24000 \\
Marginal NGCC & 920 & 22000 \\
Average Grid & 130 & 21000 \\
\hline
\end{tabular}

The figures in Table 5 were calculated by adding the $\mathrm{CO}_{2}$ emissions from fuel purchases, electricity purchases and fuel sales, based on results from the economically optimised systems found in Karlsson and Wolf (2008). The integrated system uses the advantage of an increased heat and steam demand as a basis to produce more electricity, compared to the stand-alone cases, leading to less need to purchase electricity. Also, when integrating the systems, it is possible to sell more biofuel compared to the stand-alone cases. Both these changes lead to lesser $\mathrm{CO}_{2}$ emissions in the integrated cases when compared to the stand-alone cases. 
Comparing the figures in Table 5 with those in Table 4, it can be seen that the possibility to decrease $\mathrm{CO}_{2}$ emissions is higher in the $\mathrm{CO}_{2}$ optimised systems, when the systems are integrated. The operation in the standalone cases, for Biofuel Unlimited, is the same for economic optimisation and $\mathrm{CO}_{2}$ optimisation, except for the pulp mill case. For the pulp mill, the reason for this is the possibility to change the system operation and increase electricity production in the $\mathrm{CO}_{2}$ optimisation cases, as the extra biofuel used has zero net $\mathrm{CO}_{2}$ emissions, and the purchased electricity is therefore reduced. On the other hand, the possibility to reduce $\mathrm{CO}_{2}$ emissions in the $\mathrm{CO}_{2}$ optimised system in the integrated cases, compared to the economically optimised system, is larger than in the stand-alone cases because the electricity production is increased even more, due to the increased heat and steam foundation.

In the district heating system, bark is used as base load, which generates high $\mathrm{CO}_{2}$ emissions (with the assumptions in this case when assuming biofuel being a limited resource). In the $\mathrm{CO}_{2}$ optimised system, this leads to more oil being used (which has less $\mathrm{CO}_{2}$ impact than bark), while the economically optimised system does not have the same possibility. In the pulp mill (when assuming biofuel being a limited resource), electricity production is reduced in the $\mathrm{CO}_{2}$ optimised systems, as the biofuel used to produce electricity is burdened with $\mathrm{CO}_{2}$ emissions. On the other hand, it is possible to sell biofuel, which is accentuated in the pulp mill system when $\mathrm{CO}_{2}$ is optimised, and the net sum is advantageous as regards $\mathrm{CO}_{2}$ emissions. This is also possible in the integrated system and the reduction of $\mathrm{CO}_{2}$ emissions in the $\mathrm{CO}_{2}$ optimised system, compared to the economically optimised system, is greater in the integrated cases than in the stand-alone cases because less electricity is produced (no biofuel is used for electricity production) and sales of biofuel are maximised.

All cases in Table 5 follow the same pattern as in Table 4 except Biofuel Limited, Average Grid, which in the economically optimised case is lower than the other two Biofuel Limited cases (Table 5) and higher in the $\mathrm{CO}_{2}$ optimised cases (Table 4). The economically optimised cases differ only due to the difference in $\mathrm{CO}_{2}$ emissions from electricity purchases and as the $\mathrm{CO}_{2}$ emissions for electricity purchases in the Average Grid case are lower than for both Marginal NGCC and Marginal Coal, the reduction in $\mathrm{CO}_{2}$ emissions in the Average Grid case is the lowest. The $\mathrm{CO}_{2}$ optimised cases differ according to the text in conjunction with Table 4, where the reason for the exception in Tables 4 and 5 can be found.

\section{Discussion}

The results from the MIND models in this study seem to support the assumption that IS can be environmentally beneficial. In all cases, the integrated systems generate lower $\mathrm{CO}_{2}$ emissions than the stand-alone systems. By using a computer model that optimised $\mathrm{CO}_{2}$ emissions from an industrial system, it was possible to get around some of the problems associated with the environmental assessment of IS, such as the questions of what other factors might influence the environmental impact from the participating entities, and what reference system to compare with. Since the systems we compared contained the same entities and production, and the system boundary was drawn around all entities, it was possible to avoid allocation problems and inconsistency in the comparison. However, this also means that the results from this study do not consider how the emissions from the different companies vary. This problem cannot be ignored in reality since it influences the taxes, costs and development consent for the specific companies.

The study was done with $\mathrm{CO}_{2}$ emissions as an indicator, and although this is a common way to illustrate environmental pressure in energy research, we acknowledge that the greenhouse effect is not the only environmental issue important to industry, and $\mathrm{CO}_{2}$ is not the only greenhouse gas.

One of the objectives of the MIND models was also to illustrate how the results depend on the boundary conditions set and the assumptions made. Most probably, none of the assumptions and emissions accounting models used in this study represents the objective truth about real-world conditions. For example, considering biofuel as an unlimited resource may seem unfair since it leads to the conclusion that, from a $\mathrm{CO}_{2}$ and a resource perspective, it does not matter how the biofuel is used, meaning that the efficiency of the boilers could just as well be $20 \%$ as $70 \%$ and the boilers could be 'fired for the crows' (as a Swedish saying goes) without any impact on the greenhouse effect. Nonetheless, this is an assumption that is generally made. One argument in its favour is that the biomass would otherwise decompose and emit $\mathrm{CO}_{2}$ anyway. However, this is not true for all types of biofuel and also does not account for time perspectives (i.e., that it might be argued that it makes a difference when the $\mathrm{CO}_{2}$ is released to the atmosphere). The other extreme, assigning biofuel the same value of $\mathrm{CO}_{2}$ emissions as coal, might also seem unfair since it would imply that a renewable resource is just as bad as coal. Similar arguments could be made as regards the electricity accounting models; the $\mathrm{CO}_{2}$ emissions from the average Swedish power production are very low and using those figures takes into account neither imports and exports in the deregulated market nor the effects of changes in electricity use, leading to very weak incentives to 
save electricity. On the other hand, the marginal coal model does not consider bottlenecks in the system, losses in the grid or price flexibilities (for discussions about emissions accounting from electricity, see, e.g., Grönkvist et al., 2003; Sjödin and Grönkvist, 2004).

In LCA, a distinction is usually made between consequential/change-oriented and attributional/descriptive studies, and many authors argue that average data should be used for descriptive studies, whereas marginal data should be used if studying the consequences of change in the system. However, in the cases presented here, this would imply that when describing the system, the results would show that the $\mathrm{CO}_{2}$ emissions are low, whereas closing down the system, or changing is operation from stand-alone to IS mode, would lead to significant reductions in $\mathrm{CO}_{2}$ emissions. We believe that the risk of using such a distinction is that the wrong conclusions can be drawn from a descriptive study. If a descriptive study can show low emissions from a system, the audience and the decision makers will be tempted to jump to the conclusion that nothing could be gained from changing that system, even if a change-oriented study would in fact show the opposite. On the other hand, it has been argued in the field of LCA studies that the widespread use of marginal data could lead to suboptimisations and a risk of double accounting of emissions e.g., Kåberger and Karlsson, 1998; Ekvall et al., 2005) ${ }^{3}$.

The main conclusion that can be drawn from the results in this paper is that the assumptions made are critical to the results of a study. This supports the findings of many other researchers, including Grönkvist et al. (2003), who modelled district heating technologies, and Snäkin (2003), who found large variations in the greenhouse gas emissions from the heating energy system of North Karelia, depending on the assumptions of the origin of electricity. The importance of always carefully choosing and accounting for the assumptions made must therefore be stressed. In this study, we also showed, by analysing the results from the optimisation model, how the different assumptions influence the operational strategies of the system. This also illustrates the importance of considering the level of detail of the model. Although simplification may be necessary to make the assessment operationable, some of these results could not have been seen using a simpler model.

One problem with commercially available models and programmes for environmental assessment is that some assumptions are often 'black boxes', which the executives operating them may not even be aware of. For an interdisciplinary field of research, an additional concern is that there may be different underlying assumptions that are praxis for different researchers, but unknown to others, which can lead to misinterpretations of results. Even researchers publishing in scientific papers sometimes fail to account for all their assumptions, and sensitivity analyses using different sets of assumptions and boundary conditions are very seldom made. Although one solution to these problems may be to establish detailed standards, we argue that this is difficult since different assumptions may be appropriate depending on the nature of the study. Also, since none of the models for emissions accounting and other boundary conditions can be considered to represent reality, or even to give the best approximation, standardisation is difficult. As Grönkvist (2005) argues, "To use over-simplified methods that give erroneous predictions of the outcome is counter-productive and that is why the evaluation of different methods ought to be constructive, even when it does not give a simple answer concerning which method is the best one to use.” Also, in the process of standardisation, it may be difficult to reach consensus on matters that scientists still argue about and it might also be difficult to gain acceptance for strict standards, designed to protect environmental interests, from companies and other stakeholders with different interests.

\section{Conclusions and recommendations}

In this study, we simplified the environmental assessment by including only the environmental pressure in the form of released $\mathrm{CO}_{2}$. This way, some conclusions could be made about the benefits of IS. However, the results show that there are still large uncertainties in the results depending on the assumptions made. Therefore, the value of calculating a quantitative amount of $\mathrm{CO}_{2}$ savings or emissions, using one specific set of assumptions (which may not even be accounted for), can be questioned. Although we still believe that environmental assessment methods have value as important decision-making tools, we would like to stress the importance of always accounting for assumptions. It is also recommended that different sets of assumptions, which are carefully chosen depending on the conditions and purpose of the study, be used at least for discussion and comparison and that great care be taken in choosing the proper system boundary.

\section{Acknowledgements}

\footnotetext{
${ }^{3}$ Since the $\mathrm{CO} 2$ emissions trading system started to operate in Europe, it can also be argued that for change-oriented studies in a European perspective, no $\mathrm{CO} 2$ emissions should be accounted for, since a decrease in one unit will lead to an increase somewhere else. However, we believe that it is important to show the potential to decrease CO2 through IS or other measures of efficiency, leading to an overall decrease of the emissions permits in a longer perspective. Otherwise, the Emission Trading Scheme will be counterproductive (cf. Trygg, 2006).
} 
The work was carried out under the auspices of the Energy Systems Programme, which is financed by the Swedish Energy Agency. We would like to thank Professor Mats Eklund and Associate Professor Mats Söderström for their valuable comments.

\section{References}

Ammenberg, J. (2003) 'Do standardised environmental management systems lead to reduced environmental impacts?', PhD diss., Environmental Technology and Management, Department of Mechanical Engineering, Linköping University, Sweden. Ayres, R.U. (1995) 'Life-cycle analysis: a critique', Resources, Conservation and Recycling, Vol. 14, pp.199-223.

Börjesson, L., Höjer, M., Dreborg, K-H., Ekvall, T. and Finnveden, G. (2006) 'Scenario types and techniques: towards a user’s guide’, Futures, Vol. 38, pp.723-739.

Brings Jacobsen, J. (2006) 'Industrial symbiosis in Kalundborg, Denmark: a quantitative assessment of economic and environmental aspects', Journal of Industrial Ecology, Vol. 10, Nos. 1-2, pp.239-255.

Carlson, A. (2003) 'Energy systems and the climate dilemma: reflecting the impact on $\mathrm{CO}_{2}$ emissions by reconstructing regional energy system’, Energy Policy, Vol. 31, No. 10, pp.951-959.

Chertow, M.R. and Lombardi, D.R. (2005) 'Quantifying economic and environmental benefits of co-located firms', Environmental Science \& Technology, Vol. 39, No. 17, pp.6535-6541.

Christensen, J. (2007) 'Personal information, presentation in Kalundborg, Denmark', 12 April.

Ehrenfeld, J.R. (1998) 'The importance of LCA - warts and all’, Journal of Industrial Ecology, Vol. 1, No. 2, pp.41-49. Ekvall, T. (2002) 'Editorial: Cleaner production tools: LCA and beyond', Journal of Cleaner Production, Vol. 10, pp.403406.

Ekvall, T., Tillman, A-M. and Molander, S. (2005) 'Normative ethics and methodology for life cycle assessment', Journal of Cleaner Production, Vol. 13, pp.1225-1234.

Ekvall, T. and Weidema, B.P. (2004) 'System boundaries and input data in consequential life cycle inventory analysis', International Journal of Life Cycle Analysis, DOI: http://dx.doi.org/10.1065/lca2004.03.148.

Finnveden, G. (2000) 'On the limitations of life cycle assessment and environmental systems analysis tools in general', International Journal of Life Cycle Assessment, Vol. 5, No. 4, pp.229-238.

Finnveden, G. and Ekvall, T. (1998) 'Life-cycle assessment as a decision-support tool - the case of recycling vs. incineration of paper’, Resources, Conservation and Recycling, Vol. 24, pp.235-256.

Finnveden, G. and Moberg, Å. (2005) 'Environmental systems analysis tools - an overview', Journal of Cleaner Production, Vol. 13, pp.1165-1173.

Graedel, T.E. and Allenby, B.R. (2003) Industrial Ecology, 2nd ed., Upper Saddle River, NJ: Pearson Education, Inc. Grönkvist, S. (2005) 'All CO2 molecules are equal, but some $\mathrm{CO}_{2}$ molecules are more equal than others', PhD diss., Division of Energy Processes, Department of Chemical Engineering and Technology, Royal Institute of Technology, Stockholm. Grönkvist, S., Sjödin, J. and Westermark, M. (2003) 'Models for assessing net $\mathrm{CO}_{2}$ emissions applied on district heating technologies', International Journal of Energy Research, Vol. 27, pp.601-613.

IPCC (1997) Revised 1996 Guidelines for National Greenhouse Gas Inventories, Workbook, UK Meteorological Office, Bracknell, Vol. 2.

Kåberger, T. and Karlsson, R. (1998) 'Electricity from a competitive market in life-cycle analysis’, Journal of Cleaner Production, Vol. 6, pp.103-109.

Karlsson, M. and Sandberg, P. (2007) 'The MIND method: a flexible decision support for optimization of industrial energy systems - principles and case study’, European Journal of Operational Research, http://Magnus.Karlsson@liu.se.

Karlsson, M. and Wolf, A. (2008) 'Using an optimisation model to evaluate the economic benefits of industrial symbiosis in the forest industry’, Journal of Cleaner Production, doi: 10.1016/j.jclepro.2007.08.017, Vol. 16, pp.1536-1544.

Knutsson, D., Werner, S. and Ahlgren, E.O. (2006) 'Short-term impact of green certificates and $\mathrm{CO}_{2}$ emissions trading in the Swedish district heating sector’, Applied Energy, Vol. 83, No. 12, pp.1368-1383.

Russel, A., Ekvall, T. and Baumann, H. (2005) 'Editorial: Life cycle assessment - introduction and overview', Journal of Cleaner Production, Vol. 13, pp.1207-1210.

Sandberg, P. and Larsson, M. (2006) 'Analysing the cost, energy use and environmental performance of an integrated steel plant by applying a multi-objective approach', Energy - The International Journal, in press.

SEA (2000) Electricity Market 2000, Report ET 18:2000, Swedish National Energy Administration, Swedish Energy Agency, Eskilstuna, Sweden.

SEA (2002) Marginal elproduktion och $\mathrm{CO}_{2}$ utsläpp i Sverige (Marginal Electricity Production and $\mathrm{CO}_{2}$ Emissions in Sweden) [in Swedish], Report ER14, Swedish Energy Agency, Eskilstuna, Sweden.

Singh, A., Lou, H.H., Yaws, C.L., Hopper, J.R. and Pike, R.W. (2006) 'Environmental impact assessment of different design schemes of an industrial ecosystem', Resources Conservation \& Recycling, doi: 10.1016/j.resconrec.2006.10.002.

Sjödin, J. and Grönkvist, S. (2004) 'Emissions accounting for use and supply of electricity in the Nordic market', Energy Policy, Vol. 32, pp.1555-1564.

Snäkin, J-P. (2003) 'Wood energy and greenhouse gas emissions in the heating energy system of North Karelia, Finland: an industrial ecology approach’, Academic diss., Faculty of Forestry, University of Johensuu, Finland.

Svensson, N., Roth, L., Eklund, M. and Mårtensson, A. (2006) 'Environmental relevance and use of energy indicators in environmental management and research', Journal of Cleaner Production, Vol. 14, pp.134-145.

Swedish Forest Industry Federation (2007) http://www.skogsindustrierna.org/ (accessed 11 May 2007).

Symbiosis Institute (2007) http://www.symbiosis.dk (accessed 10 April 2007).

Trygg, L. (2006) 'Swedish industrial and energy supply measures in a European system perspective', PhD diss., Division of Energy Systems, Department of Mechanical Engineering, Linköping University, Sweden. 
Tyteca, D., Carlens, J., Berkhout, F., Hertin, J., Wehrmeyer, W. and Wagner, M. (2002) 'Corporate environmental performance evaluation: evidence from the MEPI project', Business Strategy and the Environment, Vol. 11, pp.1-13.

Van Berkel, R., Willems, E. and Lafleur, M. (1997) 'Development of an industrial ecology toolbox for the introduction of industrial ecology in enterprises - I', Journal of Cleaner Production, Vol. 5, Nos. 1-2, pp.11-26.

Werner, S. (2001) 'Rewarding energy efficiency: the perspective of emissions trading', Euroheat \& Power - Fernwärme International, Vol. 30, No. 9, pp.14-21.

Wolf, A., Eklund, M. and Söderström, M. (2007) 'Developing integration in a local industrial ecosystem - an explorative approach’, Business Strategy and the Environment, doi: 10.1002/bse.485, Vol. 16, pp.442-455. 